\title{
Main functionalities of the Knowledge Practices Environment (KPE) affording knowledge creation practices in education
}

\section{Lakkala, Minna}

ISLS International Society of the Learning Sciences 2009

Lakkala , M , Paavola , S, Kosonen , K, Muukkonen , H, Bauters , M \& Markkanen , H 2009 , Main functionalities of the Knowledge Practices Environment (KPE) affording knowledge creation practices in education . in C O'Malley, D Suthers, P Reimann \& A Dimitracopoulou (eds) , [Computer Supported Learning Practices] : proceedings of the 9th International Conference on Computer Supported Collaborative Learning [CSCL2009], Rhodes, Greece, June 8-13, 2009 : Volume 1, / Editors: Claire O'Malley, Daniel Suthers, Peter Reimann, Angelique Dimitracopoulou . ISLS International Society of the Learning Sciences , pp. 297-306 , International Conference of Computer Supported Collaborative Learning (CSCL) , Rhodes, Greece , 08/07/2009 . < http://delivery.acm.org/10.1145/1610000/1600099/p297-minna.pdf?key1=1600099\&key2=5649517521\&coll=GUIDE $>$

http://hdl.handle.net/10138/18654

acceptedVersion

Downloaded from Helda, University of Helsinki institutional repository.

This is an electronic reprint of the original article.

This reprint may differ from the original in pagination and typographic detail.

Please cite the original version. 


\title{
Main functionalities of the Knowledge Practices Environment (KPE) affording knowledge creation practices in education
}

\author{
Minna Lakkala ${ }^{1}$, Sami Paavola ${ }^{1}$, Kari Kosonen ${ }^{1}$, Hanni Muukkonen ${ }^{1}$, Merja Bauters ${ }^{2}$ \& \\ Hannu Markkanen ${ }^{2}$ \\ ${ }^{1}$ Department of Psychology in University of Helsinki, P.O. Box 9, FI-00014 University of \\ Helsinki, Finland, \\ minna.lakkala@helsinki.fi, sami.paavola@helsinki.fi, kari.kosonen@helsinki.fi, \\ hanni.muukkonen@helsinki.fi, \\ ${ }^{2}$ Metropolia University of Applied Sciences, P.O. Box 4000, FI-00079 Metropolia, Finland, \\ merja.bauters@metropolia.fi, hannu.markkanen@metropolia.fi
}

A draft. To appear in the Proceedings of the Computer-Supported Collaborative Learning 2009 Conference.

\begin{abstract}
The present paper examines how to develop technology-mediated educational practices from acquisition and participation type approaches towards more sustained, collaborative knowledge creation, where students' work is organized around developing shared epistemic objects (artefacts, processes, practices). Typical forms of technologymediated collaborative practices in education are illustrated through a framework of 'stairs of collaboration' related to three metaphors of learning: knowledge acquisition, participation and knowledge creation. It is maintained that typical functionalities in existing educational webtechnologies, such as various Virtual Learning Environments (VLEs), are quite inflexible and inadequate for shared work on epistemic objects. The main focus in the present paper is on describing how a basic platform supporting collaborative knowledge creation, called Knowledge Practices Environment (KPE), has been built to provide affordances to work around epistemic objects and practices.
\end{abstract}




\section{Introduction}

A current challenge for education is to prepare learners for the emergent knowledge society through appropriate pedagogical practices that promote competencies for sharing, creating and working with knowledge and knowledge artefacts in an innovative way; such work would necessarily involve planning related processes together. Pedagogical practices that are considered to help to improve such competences include features such as student ownership and active involvement; collaboration between participants; activities of searching, sharing and elaborating knowledge; working with authentic, ill-defined problems; and critical reflection on one's own activity (Ilomäki, Lakkala \& Paavola, 2006; Kozma, 2003; Scardamalia \& Bereiter, 2003). Knorr-Cetina (2001) used the notion of 'epistemic practices' to describe such knowledge-centered activities in education and work contexts. We use the term 'knowledge practices' as a near synonym for this.

Theoretical approaches emphasizing learning activities where people are collaboratively developing new artefacts and systematically transforming their knowledge practices relate to the knowledge creation metaphor of learning (Hakkarainen et al., 2004; Paavola \& Hakkarainen, 2005). The notion builds on the two metaphors of learning - the knowledge acquisition metaphor and the participation metaphor - introduced by Sfard (1998). Knowledge creation metaphor refers to various theories that aim at understanding how to organize long-term collaboration to simultaneously develop new knowledge and related processes. We maintain that these theories, in spite of their differences, emphasize the role of mediation and the object-oriented nature of human activity, as do the knowledge building approach (Bereiter, 2002), the progressive inquiry model (Muukkonen et al., 2005), and the theory of expansive learning (Engeström, 1987). We call this approach 'trialogical' (Paavola \& Hakkarainen, 2005; Paavola \& Hakkarainen, in press) and differentiate it from those models of learning that emphasize processes within the human mind ('monological' relating to knowledge acquisition metaphor), and from those approaches emphasizing social practices or interaction ('dialogical' relating to participation metaphor). The trialogical approach develops models and tools for organizing learners' activities around shared 'objects' (such as texts, models, conceptual artefacts, but also practices) that are created for some real purpose or subsequent use, which is often not the case in conventional educational practices. Within the trialogical approach, individually performed activities and social interaction serve the longer-term processes of developing specific, concrete, shared objects, collaboratively. Shared epistemic objects and practices are not fixed objects with stable properties like materials 
typically used in educational settings, but open-ended, future oriented, and in the process of being defined by the participants (see Knorr-Cetina, 2001).

Modern information and communication technology (ICT) presents new opportunities, yet also new challenges for education. Technology enables new ways of collaboratively working with knowledge, but these possibilities also raise the question, How should technology best be implemented to serve these educational practices. Computer based media have, for a long time, been seen to support either "the information genre" or "the communication genre" in people's activities (Enyedy and Hoadley 2006); that is, existing ICT is mainly suited for sharing information ("monologues") or for supporting social interaction (“dialogues") as respective social activity. Web-based technology, however, gives new means for collaboratively developing and creating epistemic artefacts and related practices (Miettinen, 2006). Some recently developed network applications, such as wikis, have been especially designed to afford this kind of co-construction of knowledge through the Web. Consequently, modern technology is closely related to practices of working with knowledge, but also to specific ways of understanding learning; these ways are similar to the knowledge creation or trialogical view.

In the present article, we first suggest a framework that shows, concretely how various types of technology-mediated collaboration in typical educational practices can be outlined in relation to the three metaphors of learning. Then we describe how the ideas of relevant software support for collaborative knowledge creation have been implemented in a Knowledge Practices Environment (KPE), a web-based system developed in an EU funded Knowledge Practices Laboratory (KP-Lab) project (see http://www.kp-lab.org).

\section{Forms of collaboration through technology}

If it is acknowledged that one central goal in present-day education is to transform technology-mediated practices from acquisition and participation type approaches towards systematic knowledge creation practices, then the desired transformations have to be explicated in more concrete terms. For instance, what is the relevant nature of students' activities or the role and type of appropriate technology, compared to existing conventions and technologies. In the present article, we have modeled the varying forms of web-based collaboration practices by illustrating them in terms of 'the stairs of collaboration' (see Figure 1), building on the ideas of Lehto and Terva (2001). The steps in the framework are defined according to the increasing extent and complexity of collaboration that the practices reflect 
and the changing role of knowledge and technology in the process. The framework aims at defining various forms of collaboration in a practical way. Note: The same technologies can be used is many ways; 'typical technology used' does not imply a deterministic relationship between the technology and level of practice but suggests 'prototypical' practice. Naturally, frameworks of this kind are always simplifications, but the purpose is to provide new conceptual means for analyzing basic forms of knowledge practices and relevant features of supporting technology.

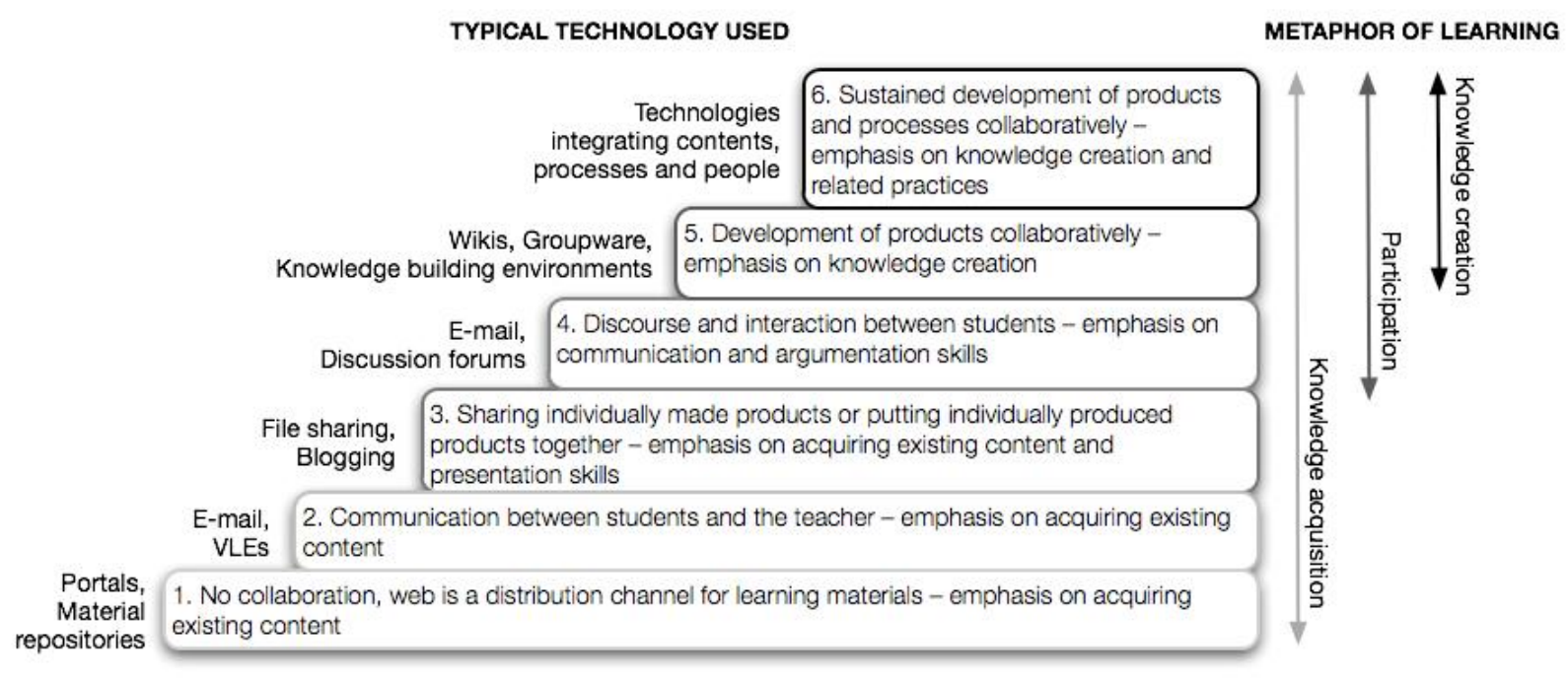

Figure 1. Stairs of web-based collaboration practices in education.

The lowest step in Figure 1 represents practices where the network serves as a transmission channel of educational materials without any communication between actors; for example self-study tutorials made available through a portal in the Internet. On the second step, the interaction occurs only between the teacher and the students; students are not at all in contact with each other. This kind of practice is actualized, for example, in educational units where students submit their task accomplishments to the teacher through some VLE, and the teacher sends individual feedback for each student through e-mail. Usually, individual learning and adoption of certain contents is emphasized in both forms of practices.

In the practices described from the third step upwards, students are also in direct interaction with each other. Typical practices representing the third step are, for example, assignments where the students first prepare written material about some topic individually, and then share the outcomes for all to read through some file-sharing system. Students might also write some comments to each others' work afterwards without actually interacting with 
each other or without revising their texts according to the feedback. The creation of material during the course can itself be a very demanding task for the students, but actual collaboration between the students remains minor, if the outcomes are distributed only for reading.

The fourth step describes practices where students are directly and reciprocally interacting and communicating with each other. It has been a very popular way in various educational settings to use web-based technology for assigning students to discuss, within that environment, various themes relating to the course topic through 'discussion forums' (Dysthe, 2002; Schrire, 2004). The organization of discussions can be quite loose, or alternatively more structured according to some sub-themes or communication and argumentation principles (Andriessen, 2006). Often the primary objective in such activities is to let students practice communication or argumentation skills; these include presenting and defending one's own opinions, accepting different viewpoints or constructively arguing and commenting on each others' ideas. Naturally, students are also expected to learn something about the topics that are the object of discussion.

The most challenging type of collaborative work occurs, in the fifth and sixth steps, when collaborators attempt to produce and modify concrete products or outcomes as the result of shared efforts; all members are assumed to participate in and take responsibility of commenting, planning, revising and developing common sketches and versions of the products. The outcome of such activity can be, for example, a common written report on a chosen subject, a design product, or a solution to an open problem that is framed together. The fifth step in Figure 1 refers to such activities where students' working is directed to the development of some epistemic objects. In the sixth step, the collaborative process, the way of working itself, in addition to the shared knowledge objects, is also subject to joint reflection and development. In such practices, students are assumed to learn the multidisciplinary content, practice communication and interaction skills; in general, they are to develop competencies and metaskills for collaborative knowledge creation in an integrated manner.

\section{Mediating role of technology in knowledge-creation practices}

The multifaceted role of technology in enhancing knowledge-creation practices can theoretically be modeled through different types of mediation. In the present article, technological design solutions are described and clustered under the following mediation types (we reformulate the types of mediation introduced by Rabardel and Bourmaud, 2003; see also Hakkarainen, 2008): 
- Epistemic mediation: creating, transforming, organizing and linking knowledge artefacts;

- Pragmatic mediation: planning, organizing and coordinating working processes;

- Social mediation: managing social relations around shared objects and linking people; and

- Reflective mediation: making visible and reflecting on the work processes.

We maintain that currently available tools (such as e-mail or file sharing systems) or VLEs (BSCW, Moodle or Blackboard) provide only limited support for collaborative knowledge creation because they typically provide functionalities only for information sharing and participation in social communication. In existing VLEs, epistemic objects often remain static and isolated, without possibilities for users to explicate relationships between them, rearrange them or build on them over a longer term. There are few existing educational applications that are generally targeted for knowledge creation. Most well known is Knowledge Forum (KF), developed for knowledge building practices (Scardamalia \& Bereiter, 2003). KF has inspired the development of KPE because it provides a knowledge space with many functionalities to create, link and build on shared multimedia objects. Another system, FLE3, was developed for progressive inquiry practices (Muukkonen, Hakkarainen \& Lakkala, 1999; Leinonen, Kligyte, Toikkanen, Pietarila, \& Dean, 2003). It includes tools supporting virtual inquiry discourse as well as the sharing, co-construction and versioning of digital artefacts. Both systems emphasize issues within epistemic mediation. Usually the tools do not include functionalities for planning and coordinating processes or integrating people, contents, and processes in a flexible and transparent way. In a review concerning new Collaborative Environments (CE), the New Working Environments Unit of the Directorate General Information Society and Media of the European commission summarized in its report,

the characteristic of current $\mathrm{CE}$ is that they are not integrated and inter-operational, that they support mainly point to point and not multipoint conferencing, that they are defined mainly for structured environment providing static artefacts and that they do not support the unstructured orchestration of activities using collaboration aware objects. Finally they focus primarily on peer communication and not flexible team interaction. (New Collaborative Working Environments 2020, 2008, p. 10) 
The emerging tools based on Web 2.0 and semantic web technologies address the above challenges of collaborative environments. While many outstanding tools are already available, they are not easily usable in an integrated manner by learners and educators who do not have enough resources or competencies to appropriate the possibilities of these diverging tools for their needs. Due to poor interoperability, integrating state-of-art tools is also technically difficult and often requires software re-engineering, which in turn makes maintenance of the systems more difficult.

\section{Features in KPE to provide affordances for collaborative knowledge creation}

In this section, we describe a web-based application, Knowledge Practices Environment (KPE), which is designed to provide specific affordances for joint development of concrete, epistemic objects as well as for planning, organizing and reflecting on related tasks and user networks (see Markkanen et al., 2008). With KPE, users are able to build collaboration environments by creating and configuring the means, as opposed to operating in predefined structures, of the common practice. KPE is a virtual environment that includes a set of basic, integrated tools (e.g., working spaces with real-time and history-based awareness, wiki, note editor, commenting, chat, semantic tagging and semantic search) for working with the shared knowledge objects.

KPE enables object-bound and threaded commenting on all items (task items, files, web-links, notes) in a shared space, as well as viewing of knowledge objects and their relations from several perspectives. Three basic perspectives are content, process and community views. Various tools and functionalities are highly integrated in the basic views to enable versatile and flexible connection, organization and reflection on all information related to the knowledge objects, processes and people concerned. Below, the basic functionalities of KPE that provide affordances for collaborative knowledge creation practices are described, in clusters according to the envisioned types of mediation. Some screen shots that are presented to exemplify the software are picked from real course settings. Some features were not yet tested in authentic settings because of their impending release only in autumn 2008; therefore, an illustration of possible usage is built into the figures.

\section{Work with knowledge artefacts}

Epistemic mediation is supported in KPE by functionalities that enable users to create, modify and organize various knowledge artefacts as well as their relations, in versatile ways. Below, 
some central characteristics related to the work with knowledge artefacts are briefly described.

\subsection{Sharing and co-construction of knowledge artefacts with free visual arrangement and linking}

In KPE, user groups can create 'Shared spaces' through which various knowledge artefacts can be shared and co-constructed. Like in any VLE, users can upload any type of files or weblinks into shared spaces. But instead of providing only a space to store and manage vast number of documents, KPE enables the users to organize knowledge objects (represented by graphical icons) through flexible, visual representations. A central view in KPE for working on knowledge artefacts is the Content view that allows free visual arrangement and linking of its content (see Figure 2). KPE is not based on folder structures or hierarchical presentation of the content; it does not hide the content into folders, which detach items from their relations. Visual organization is supported by various mechanisms, such as spatial arrangement and linking of items, filtering of items based on metadata and tags, the creation of user defined views ("tailored views") as well as the creation of visual models on top of existing views.

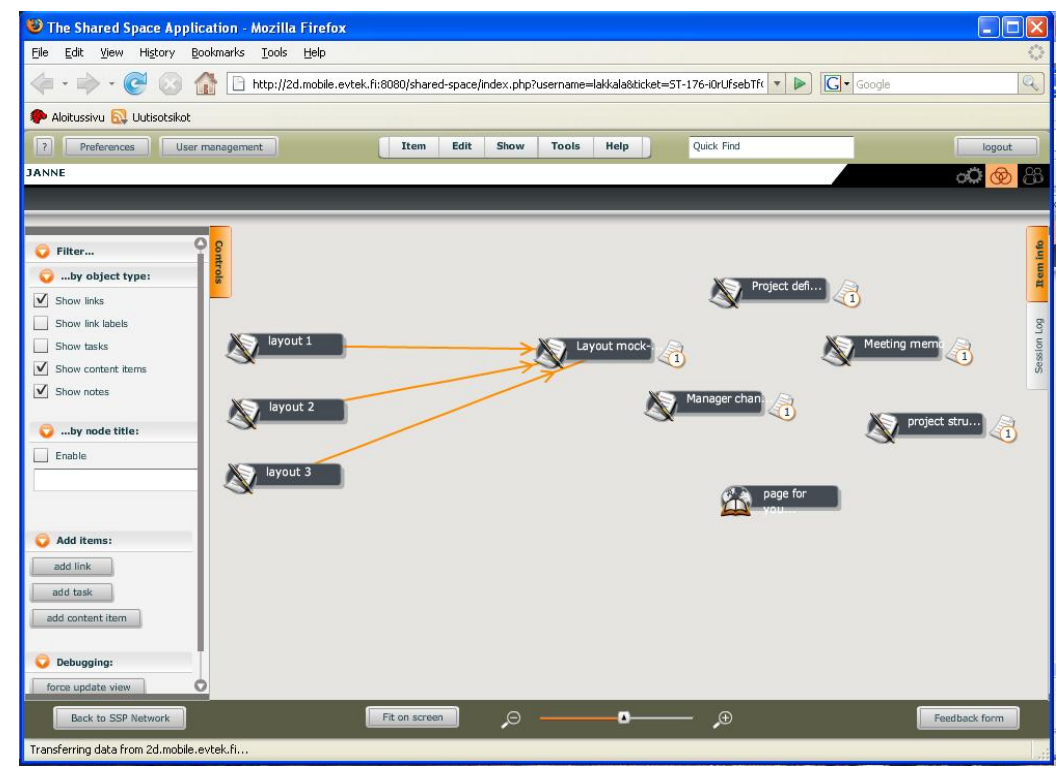

Figure 2. Visual arrangement of content items in one student team from a design course in Media Education in Metropolia University of Applied Sciences, Finland.

In addition to a possibility to upload files in a Content view, some specific tools are built in or integrated in KPE to support easy production of texts and sketches as well as coediting and comparison of text versions. With Note editor, users can directly write their ideas 
and thoughts as content items in a shared space, without the labor of creating and uploading an external text file (Furnadziev, Tchoumatchenko, Vasileva, \& Lakkala, in press). All members of a space can open and edit the created notes and view their previous versions. Furthermore, users can open many notes simultaneously for comparison and integration, and link notes to other content items in the Content view (see Figure 3). The implementation of Note editor in KPE is a simple but powerful tool for collaborative knowledge creation; it draws on the idea in Knowledge Forum (Scardamalia \& Bereiter, 1994), that to foster knowledge building, one proceeds through idea generation and elaboration using textual notes. The Content view also includes a Sketch pad tool that is based on the same idea as Note editor, but which enables creation, co-editing and versioning of simple drawings and visual sketches. In addition, KPE affords groups the ability to write collaboratively in an integrated wiki. A wiki document can be created as a content item in the Content item view, which offers the possibility to access the same wiki document from a shared space. The progress and changes made to the document are visible to all group members.

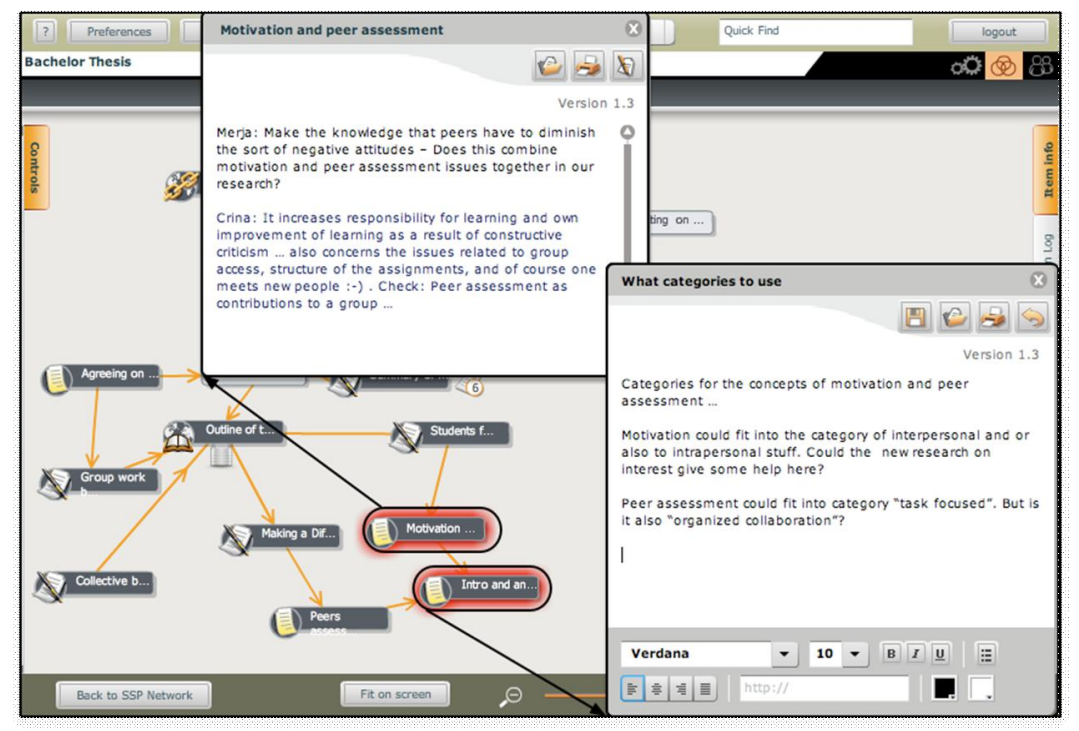

Figure 3. Illustration of Note editor with two notes opened simultaneously.

\section{2 "Object-bound" interaction around knowledge artefacts}

In the Content view, object-oriented collaboration is emphasized by content-bound commenting functionality (see Figure 4) that allows asynchronous, threaded discussions attached directly to knowledge objects. One object can have many comment threads, thus enabling users to discuss various aspects of the objects, directly, in context. This objectoriented aspect places KPE beyond isolated discussion forums, threaded notes or 
argumentative discussion supports, which concentrate on the dialogical aspect of collaboration and so lose the context; KPE answers the need to have individual contributions attached in collaborative work that is organized around shared knowledge objects embedded and embodied in a shared space. Similarly, object-bound chat enables synchronous interchange attached directly in the content items at hand. Chat log is saved and linked to the targeted content item, therefore keeping the log attached to its object for possible re-use and continuation.

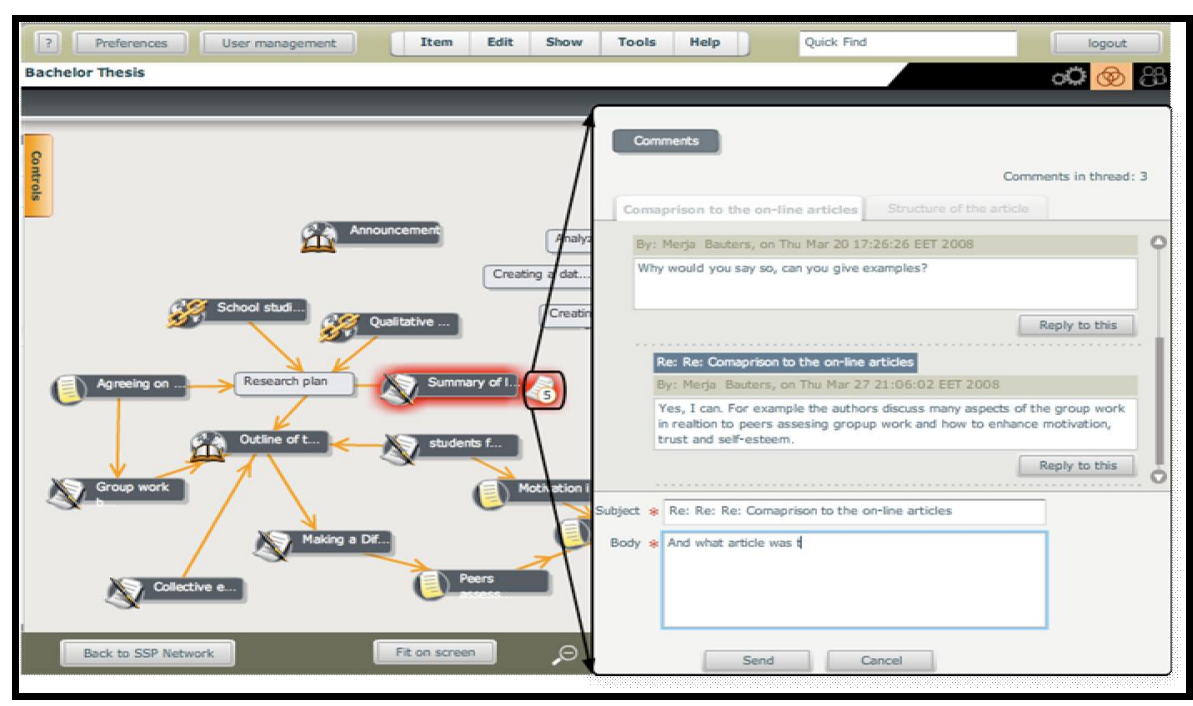

Figure 4. Illustration of content-bound commenting

\subsection{Flexible use of metadata, tags and ontologies}

One aspect of KPE that goes beyond current learning environments is the use of metadata and semantic features to support the usage and integration of knowledge artefacts in various ways. Tags and tag vocabularies can be created and edited by participants, or be taken from readymade vocabularies. In the Content view, all items can be tagged. This provides additional affordances for various types of knowledge practices in education, as compared to existing tools. For example, in typical research seminars, semantic tagging can be used to help students find common areas of interest and related materials or to analyze the elements and concepts of existing and produced research papers. In addition, the tags or concepts that users define are implemented in the underlying technology in a way that allows search through the semantics or relations between tags; e.g., semantic information can be reused across various integrated tools. Such functionalities allow the users to create their own cognitive and conceptual tools and instruments based on the potentialities of the semantic web. 


\section{Organizing processes}

Pragmatic mediation has been central in the design of the functionalities of KPE for planning, monitoring, and regulating joint activities and working processes. These functionalities enable users to define tasks, draft visual representations of processes, as well as they provide users with 'awareness features' (see below) of the activities in the spaces.

\subsection{Process planning through defining tasks and drafting visual process representations}

In addition to content items, in KPE, users can explicitly define, modify and arrange task items to fit their process and domain, including, e.g., descriptors of title, responsible users, start and end dates, and status. This feature allows users to explicate their process elements and promotes responsibility and ownership over their decisions and actions. In the Content view, task items can be presented, linked and arranged in the same visual representation together with the content items, which provides users with a holistic view of their knowledge creation processes, without separating tasks from contents (see the left screen shot in Figure 5). Spatial representation and emphasis on relationships between tasks as well as tasks and contents is especially useful in educational settings, where the chronology of the work is not essential, but there is a requirement to see connections, associations and causal relations between the various elements of the process.

The same tasks that are displayed in the Content view with their relations to content items can be viewed in Process view, presently in the form of a GANTT chart (see the right screen shot in Figure 5). The Process view enables users to plan tasks and processes in a chronological manner as well as to monitor how the required tasks have been accomplished. For instance, in courses that teach collaborative design practices, where real design projects are executed, it is highly important (for flexible adjustment of the process) that participants be able to monitor the progression of the project and modify the tasks. Again, interdependencies and mutual connections between the tasks defined in the Process view are in turn automatically converted by the system into graphical constructions representing these connections in the Content view. 


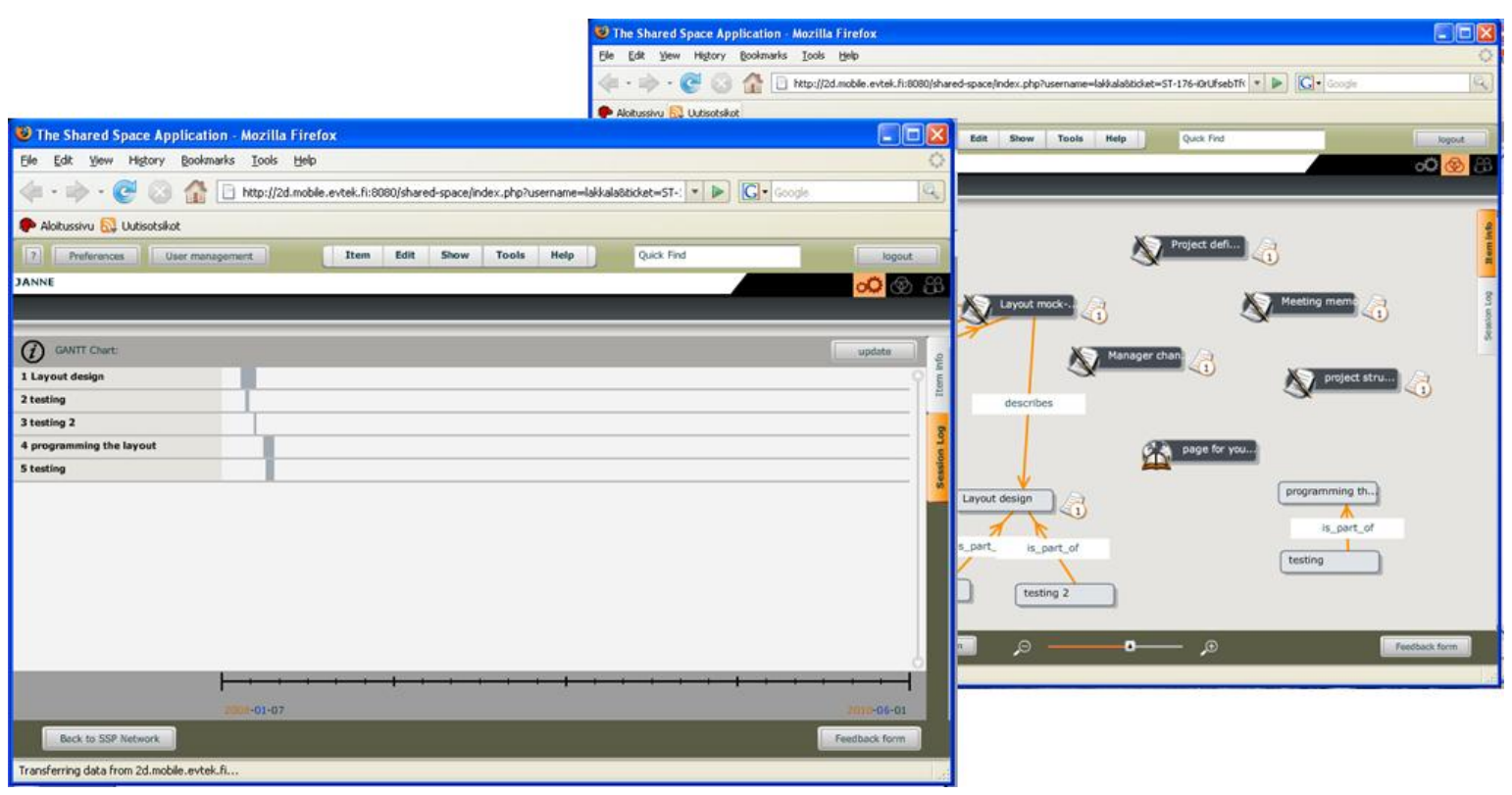

Figure 5. Right: Spatial arrangement of knowledge artefacts in the Content view including content items (black), tasks (grey) and labeled relations. Left: The Process view presenting the same tasks in a GANTT chart.

\subsection{Features for focussed work on particular knowledge objects and tasks}

The management of knowledge creation processes is further supported in KPE by the use of tailored views, into which the users can transfer selected parts of the process (tasks and content items, links, etc.) from the Content view to work within a particular theme or phase of the process in a focused manner. Tailored views provide another visual means to organize knowledge creation processes by enabling users to arrange shared knowledge objects according to a background image or visual structure that presents the different parts of the process (e.g., certain phases in a pedagogical approach used). Tailored views support processes in which a particular topic requires deepened focus, without the abundance of all the material (e.g., inquiry-type practices) or where particular phases need to be conducted separately in order to be able to move to the next phase (e.g., project based practices).

\subsection{Awareness features to aid process planning and coordination}

Planning and coordination of a collaborative working process, be it asynchronous or synchronous, will highly benefit from awareness features that help in explicating tacit knowledge related to one's own or others' working practices. Often awareness features are not consciously noticed or paid attention to; however, they may play an essential role in toolmediated collaboration, keeping track of on-going and past actions. Without such information, 
the work may be severely hindered. Awareness features in KPE are meant to support synchronous work are, for example, visual clues and on-line notifications about who is online, who is working with whom, or who is working on what object and how (see Figure 6). Historical perspective is provided, e.g., by a list about modifications of knowledge objects and tasks or by e-mail or mobile device notifications about the events in a shared space.

\section{Social relations around shared objects and processes}

In KPE, social mediation is envisioned in functionalities that support users in maintaining their contacts and keeping up with changing information about other participants, as well as their relations to the shared processes and content items. Social mediation provided by the tools allows users to lean on each others' competencies, expertise and experience and help them align their thoughts and actions with those of others.

\subsection{Organizing social structures, responsibilities and roles}

For the smooth coordination of collaborative work, it is crucial to explicitly define the social structures among the participants, such as groupings, responsibilities and roles. To begin with, for each content or task item visible in the Content or Process views, it is possible to define persons responsible for that item. In addition, a third basic view of KPE, called the Community view (see Figure 6), is especially meant to support the coordination of tasks and responsibilities between participants. It presents a list of users with indications who is on-line. Detailed user information includes a list of all tasks and knowledge objects that have been created and modified by or assigned to a particular member. The awareness features mentioned above include clues and notifications of each user's status as well as past and present activities. The flexibility of social structures is increased by allowing users to define various roles and access rights to participants, in order to alter the prominent practice, in many virtual learning environments, of predefining fixed teacher and student roles. 


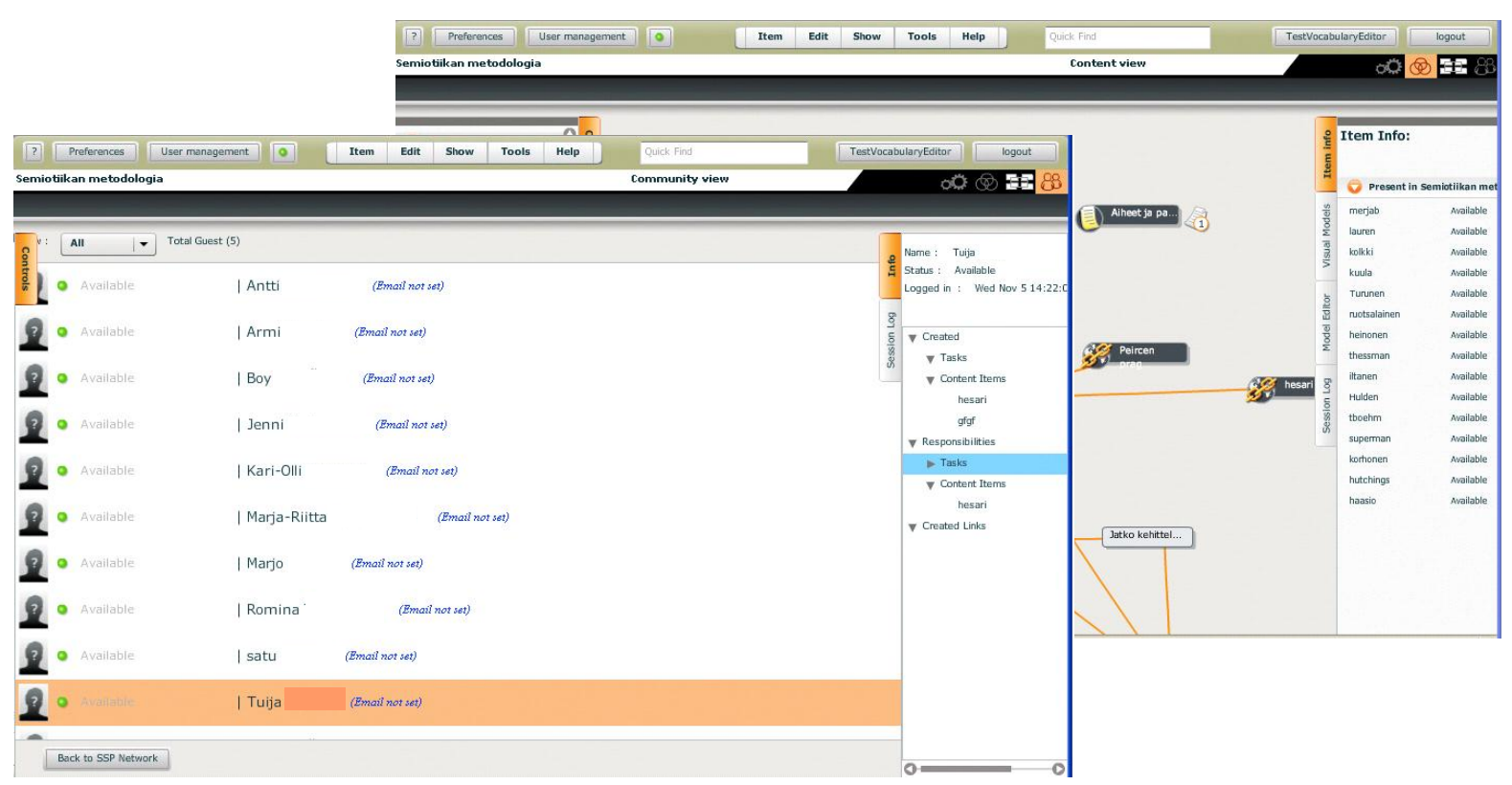

Figure 6. Left: The Community view. Right: Information about on-line users in the Content view.

\subsection{Integrated communication means and social clues}

As mentioned above in relation to epistemic and pragmatic mediation, KPE offers means to keep in contact with others, such are asynchronous commenting possibilities, or general chat and context bound chat to enable synchronous discussions. Awareness features include clues and notifications of participants' status or past and present activities. In addition, the integrated Meeting Management tool (M2T) enables creation and preplanning of meetings as well as formulation of meeting templates for further use. All these tools are meant to suppor the planning and organization of ongoing activities in an integrated way, not only from each participant's private perspective, the latter being the dominant manner we have observed in current, virtual learning environments.

\section{Reflecting on processes for deliberate transformation of knowledge practices}

The last of the four types of mediation enables actors to reflect on and evaluate their joint activities as well as the shared objects being created and modified collaboratively. The aim is to provide user groups with information that allows them to take the community's knowledge creation processes as an explicit object of shared reflective activity and, consequently, elicit deliberate transformation and improvement of their joint knowledge practices. The reflection 
is afforded in KPE in many ways by the above mentioned and additional functionalities (e.g., visual representations, awareness tools or analytical services).

\subsection{Reflecting on the on-going processes through visual representations and awareness tools}

One virtue of the visual representations of content items (and related processes) is that they provide users an overall, graphically supported overview of current state of the shared space for the critical evaluation of the process. In addition, the various awareness functionalities, mentioned above, enable users to keep track of the process progress and perceive what is going on with the shared objects and tasks, see what the others are up to, but also acquire offline information about events and on-going activities.

\subsection{Reflection and analysis of past processes through analytical services}

Various analytical services in KPE will provide users with possibilities to reflect on the process from a historical perspective. Especially for researchers and teachers, KPE provides functionalities for exporting the available data from a knowledge repository, covering all changes made in the selected part of the knowledge practices environment for a specified period of time (Data export tool) and use external data analysis tools to evaluate the data. One means to monitor what is going on within the working environment and to reflect on the community's practices will be knowledge evolution analysis that gives information about the evolution of contents and work processes. Methods of social network analysis are utilized for presenting and visualizing various social processes that emerge between people as well as people and artefacts through KPE.

\section{Results from field trials piloting KPE in educational settings}

In the spring and autumn terms in 2008 , a few pilot studies were conducted in the University of Helsinki and in the Metropolia University of Applied Sciences to examine the utility of test releases of KPE in authentic course settings. Below, some results from two experiments are briefly reviewed. Note that the technology was still under development during the time of studies; therefore the experiences and results are mainly indicative.

In Metropolia, KPE was used by second year Media Engineering students in a term project, through which they are expected to improve their practices in managing projects and dealing with real situations, while designing a product or service for a real client. The 
functionalities of the Content view and the Process view were in use for mediating the collaborative creation of design artefacts (epistemic mediation) as well as process planning and coordination (pragmatic mediation). According to the analysis of student teams' shared spaces in KPE (see also Jalonen, Kosonen \& Lakkala, in press), the possibility for visual mapping of shared knowledge objects was used for explicating the structure and logic of the teams' design process. Students reported that the visual, open and easily modifiable Content view helped the sharing and versioning of documents as well as organizing and getting an overview of the process. There was also challenges because the changes made to the shared view required explicit coordination and mutual decisions between the team members. According to one interviewed student team leader, the current version of the GANTT chart in the Process view was usable for general planning of the design project, but it lacked many functionalities that are central in process planning, such as more informative timeline or a possibility to define dates in the more detailed level. In general, student teams appeared to resort to a fairly strict division of labor when organizing their team work, instead of collaboratively working on their design documents.

In the University of Helsinki, KPE was used in a bachelor year methodology course on semiotic studies. In the course, students wrote scientific reports in pairs. The Note editor, commenting functionality and tailored views were suggested to be used for co-constructing questions, ideas and versions of the report. According to the observations, the use of Note editor to formulate questions and to comment on others' questions did aid the students to grasp the relevance of generating research questions. In the course feedback, the students mentioned that they considered the functionalities to be useful for their inquiry task. The linking was reported to be used for two purposes: to visually organize artefacts in the Content View and to define which artefacts were based on which artefacts; i.e., explicate the evolution of artefacts. One intriguing notion is that, from observations, it appeared that the students were not using the linking much, but in the course feedback, linking was mentioned as important. Tailored views were not used as much as was envisioned, since it appeared to be hard for the users to operate with them. The visibility of all artefacts in the Content View was considered good for sharing artefacts, but also confusing. The search and recent changes functionalities were still lacking from KPE during the course, which apparently caused a feeling of confusion about managing all artefacts. The students pointed out that they missed the search and recent changes functionalities to 'know what has appeared in the space since last time'. The possibility of having synchronous chat sessions integrated with the shared space (see Furnadziev, Tchoumatchenko, Vasileva, Lakkala \& Bauters, in press) was 
appreciated for keeping contacts with other students of the course, and with the partner writing the same report; however, not all students found the chat tool. Furthermore, clearer guidelines were asked by the students for the usage of KPE. In general, it appears that the students were positively surprised about the amount of comments and feedback they received through KPE during the process of writing their report. We may conclude that the Note editor, commenting and linking functionalities both helped to organize the artefacts (epistemic mediation) and promoted reflection (reflective mediation). In addition, it could be stated that the possibility to keep contact by integrated chat was important, especially in this kind of course, where the students come from various disciplines and the course meetings are the only possibility to meet each other face-to-face (social mediation).

\section{Discussion}

The functionalities of the Knowledge Practices Environment, described in the present article, are developed in co-design processes integrating theoretical ideas, pedagogical research and technological development, based both on the viewpoints of the "trialogical" approach to learning, and previous research and experiences with existing tools. The functionalities were described by structuring them according to the theoretically motivated types of mediation. Much of the added value of KPE is the high integration of various functionalities to build an integrated and flexible virtual collaboration environment for various uses. The purpose of the integrative combination of these functionalities is to allow users to be engaged in sustained collaborative processes for creating knowledge items or domain models, as well as for planning and reflecting on their practices.

The Knowledge Practices Environment as a context for collaborative knowledgeintensive working processes is based on the notion that knowing and learning in the complex contemporary world largely rely on collaborative creation, evaluation, modification, and implementation of resources, practices and representations. With KPE, user groups can implement and customize available tools and resources for their own purposes. Epistemic and pragmatic mediation embedded in the KPE enable the integration of users' collaborative and individual efforts in creating material artefacts and coordinating their activities. Social mediation, provided by some functionalities, allows users to lean on each others' competencies, expertise and experience and helps them align their thoughts and actions with those of others. Reflective mediation is afforded by various means for viewing and monitoring the transformation of knowledge content, activities and social relations. 
$\mathrm{KPE}$ is a part of a larger, integrated KP-Lab system, developed in the KP-Lab project for five years (2006-2011); this paper only provides a snapshot of the achievements so far. The KP-Lab system is ontology driven and provides a platform to develop advanced semantic tools for collaborative learning. The first prototypes of a semantic multimedia annotation tool and an editor for visual models and visual modeling languages (used for collaborative semantic modeling) are released for field trials. All KP-Lab tools are based on a foundational data model that provides common semantics for the tools and platform services. It is extended by the tool ontologies in order to describe the more specific semantics required.

In addition to on-going technical development, a necessary next step in the KP-Lab project will be the testing of the utility of the tools and developing pedagogical models, widely, in various educational and workplace settings. The true affordances of the designed tools and functionalities for mediating real knowledge practices and their development can be evaluated only when the fully functional tools are available throughout the real knowledge creation process.

\section{References}

Andriessen, J. (2006). Arguing to Learn. In K. Sawyer (Ed.), Handbook of the Learning Sciences (pp.443-459). Cambridge: Cambridge University Press.

Bereiter, C. (2002). Education and mind in the knowledge age. Hillsdale: Erlbaum.

Dysthe, O. (2002). The Learning Potential of a Web-mediated Discussion in a University Course. Studies in Higher Education, 27(3), 339-352.

Engeström, Y. (1987). Learning by expanding. Helsinki: Orienta-Konsultit.

Enyedy, N., \& Hoadley, C. M. (2006). From dialogue to monologue and back: Middle spaces in computer-mediated learning. Computer-Supported Collaborative Learning 1(4), 413-439.

Furnadziev, I., Tchoumatchenko, V., Vasileva, T., Lakkala, M., \& Bauters, M. (in press). Tool for synchronous communications in collaborative knowledge practices environment (KPE). Proceedings of the V International Conference of Multimedia and Information and Communication Technologies in Education (m-ICTE 2009).

Furnadziev, I., Tchoumatchenko, V., Vasileva, T., \& Lakkala, M. (in press). Tools for Document Centred Collaboration in Shared Space. Journal of Elektronika and Elektrotehnika. 
Hakkarainen, K. (2008) Features of trialogical learning: An introduction of research and development of Knowledge-Practices Laboratory (KP-Lab). Internal working paper for the KP-Lab project.

Hakkarainen, K., Palonen, T., Paavola, S. \& Lehtinen, E. (2004). Communities of networked expertise: Professional and educational perspectives. Advances in Learning and Instruction Series. Amsterdam: Elsevier.

Ilomäki, L., Lakkala, M. \& Paavola, S. (2006). Case studies of learning objects used in school settings. Learning, Media, and Technology, 31 (3), 249-267.

Jalonen, S., \& Kosonen, K., \& Lakkala, M. (in press). Analyzing technology-enhanced knowledge practices in an engineering course. Proceedings of the CSCL 2009 conference.

Knorr Cetina, K. (2001). Objectual Practice. In T. R. Schatzki, K. Knorr Cetina, \& E. von Savigny (Eds.), The Practice Turn in Contemporary Theory (pp. 175-188). London and NY: Routledge.

Kozma, R. B. (2003). Technology and classroom practices: An international study. Journal of Research on Technology in Education, 36(1), 1-14.

Lehto, T., \& Terva, J. (2001). Verkot ja yhteisöllisyyden kehittyminen: merkitys aikuiskoulutukselle. In P. Sallila \& P. Kalli (Eds.), Verkot ja teknologia aikuisopiskelun tukena (pp. 98-116). Jyväskylä: Gummerus Kirjapaino Oy.

Leinonen, T., Kligyte, G., Toikkanen, T., Pietarila, J., \& Dean, P. (2003). Learning with collaborative software - A guide to FLE3. Helsinki: University of Art and Design. Retrieved from http://fle3.uiah.fi/papers/fle3_guide.pdf (March 8, 2009).

Markkanen, H., Holi, M., Benmergui, L., Bauters, M., \& Richter, C. (2008). The Knowledge Practices Environment: a Virtual Environment for Collaborative Knowledge Creation and Work around Shared Artefacts. In Proceedings of World Conference on Educational Multimedia, Hypermedia and Telecommunications 2008 (pp. 5035-5040). Chesapeake, VA: AACE.

Muukkonen, H., Hakkarainen, K., \& Lakkala, M. (1999). Collaborative technology for facilitating progressive inquiry: Future Learning Environment Tools. In C. Hoadley, \& J. Roschelle (Eds.), Designing new media for a new millennium: Collaborative technology for learning, education, and training (pp. 406-415). Mahwah, NJ: Erlbaum. 
Muukkonen, H., Lakkala, M., \& Hakkarainen, K. (2005). Technology-mediation and tutoring: how do they shape progressive inquiry discourse? Journal of the Learning Sciences, 14(4), 527-565.

New Collaborative Working Environments 2020 (2008). Report on industry-led FP7 consultations and 3rd Report of the Experts Group on Collaboration@Work. Retrieved from

http://ec.europa.eu/information_society/activities/atwork/hot_news/publications/docu ments/new_collab_environments_2020.pdf (March 8, 2009).

Paavola, S., \& Hakkarainen, K. (2005). The knowledge creation metaphor - An emergent epistemological approach to learning. Science \& Education, 14, 535-557.

Paavola, S., \& Hakkarainen, K. (in press). From meaning making to joint construction of knowledge practices and artefacts - A trialogical approach to CSCL. Proceedings of the CSCL 2009 conference.

Rabardel, P., \& Bourmaud, G. (2003). From computer to instrument system: a developmental perspective. Interacting with Computers, 15(5), 665-691.

Scardamalia, M. \& Bereiter, C. (2003). Knowledge building. In Encyclopedia of Education, Second edition (pp. 1370-1373), New York: Macmillan Reference.

Scardamalia, M., \& Bereiter, C. (1994). Computer support for knowledge-building communities. Journal of the Learning Sciences, 3(3), 265-283.

Schrire, S. (2004). Interaction and cognition in asynchronous computer conferencing. Instructional Science, 32, 475-502.

Sfard, A. (1998). On two metaphors for learning and the dangers of choosing just one. Educational Researcher, 27, 4-13.

\section{Acknowledgments}

The reported work is developed within the framework of KP-Lab Integrated Project (http://www.kp-lab.org), sponsored under the 6th EU Framework Programme for Research and Development. The authors are solely responsible for the content of the article. It does not represent the opinion of the KP-Lab consortium or the European Community, and EC is not responsible for any use that might be made of data appearing therein. We wish to thank the three anonymous reviewers and Hal White who helped improve the text. 